\title{
Problems and Path Exploration on Full-time Primary Education Specialty Master Training
}

\author{
Haiyue $\mathbf{Q u}^{\mathrm{a}}$, Jun Yang \\ School of Education and Sports, Bohai University, Jinzhou, 121013, China \\ a714581417@qq.com, b444530141@qq.com
}

Keywords: full-time; primary education; educational master; problems; path exploration

\begin{abstract}
The goal of full-time primary education master degree in our country is cultivating primary school teachers with professional competence. However, there are still many problems in the process of training: imbalanced curriculum module structure, single teaching methods, practical teaching link is 'anemia', and "double-tutor system" exists in name only. For this purpose, the exploration is highlighting the characteristics of primary education as the core, optimizing the curriculum structure; taking multiple interactions, enriching teaching methods; establishing rigorous assessment procedures, improving "double-tutor system"; through U-S symbiotic cooperation for injecting nutrition to the practical teaching and other paths, the quality of primary school education masters training promote the professional development of teachers.
\end{abstract}

\section{Introduction}

In 2009, the Ministry of Education establish full-time education specialty master degree, China's full-time primary education specialty master degree began to recruit students, in order to master the modern education theory, become high-quality primary school teachers with strong teaching practice and research ability, in line with today's social demand for high-level practical specialized talents. As China's Master of Education is a new degree, in many ways there are still deficiencies, positioning their training objectives, combing full-time education, mastering training process problems, exploring the professional specialty of full-time education master's training path is imperative.

\section{Targets on Full-time Primary Education Specialty Master Training}

Full-time primary school education specialty master's training target is the training course of its action guide, restricting the entire training activities of all links. Although the goal of "Full-time Education Master's Degree Graduate Student Training Program" will be identified as " of cultivate high-quality primary and secondary school teachers with the mastery of modern education theory, with strong practical educational teaching practice and research ability", each training departments also should strictly follow the training objectives. However, there are two obvious extremes in the training objectives of full-time primary education masters in China: one that converges to the academic master's training objectives. Another is to dwarf into purely vocational skills. These two extremes lead to full-time primary school education specialty master training concept more and more away from the primary education of the original demands. Therefore, on the basis of fully considering the characteristics of the degree, the unique requirements of the basic education for the quality teachers and the inherent laws of the full-time education master's training activities, the training objectives should realize the dualism of "professional competence" and "research ability" and position it as primary school teachers with the training of professional researching competence[1].

(1) Cultivate primary school teachers with professional competence. In 2010, the "Master and Doctor Professional Degree Program for Graduate Education Development" clearly stated: "Professional degree is the specific independent education model with specific career orientation for 
the specific needs of the community." The professional competence is the sum of the knowledge, ability, and personality traits of the individual who have achieved excellent job performance in the particular occupation. [2] As one of the professional degree, full-time primary education specialty master's degree training should have a clear career orientation, directly face to the basic education needs, cultivate and guide the basic education of outstanding teachers, emphasizing the orientation of practice, training objectives are to improve the professional competence of full-time primary education specialty master's degree.

(2) Cultivate primary school students with research competence. Cultivate primary school teachers with research competence. Although the professional degree emphasizes the applicability and career background, but its essence is academic and professional combined closely. Training full-time primary education specialty master's professional competence at the same time, but also cultivate strong education and teaching research interests and the spirit of exploration, the formation competence of awareness problem and specific educational teaching scene problems. Graduate education "scientific research as the chief component, the role of students is to combine scientific research and learning activities into a kind of learning model [3]. "

\section{Existing Problems on Primary Education Master Training}

As the training of full-time primary education master in our country start late with less experience, there are many difficulties in the training process, resulting in primary school education master fell to lack of both academic master's theoretical reserves and professional master's practical ability in passive situation, seriously hampered the quality of our teachers.

(1) Imbalanced curriculum module structure. In 2009, the "Development Program" promulgated by the Academic Affairs Office of the State Council stipulated: "curriculum provision should reflect the principle of combining theory with practice into four basic modules: degree basic course, professional compulsory course, professional elective course and practice teaching course. In our country, full-time primary education master development program, degree basic course is total 12 credits, including "Foreign Language", "Political Theory", "Educational Principles", "Curriculum and Teaching Theory", "Primary and Secondary Education Research Methods", "Youth Mental Development and Education "and other six courses. Professional courses and professional elective courses are designed by the training units based on their own characteristics, each subject direction usually set up "Primary School Language Courses and Teaching Research" and other five professional compulsory courses, each course 1-2 credits, in total 10 credits. It can be seen that the proportion between the professional curriculum and the public curriculum in the curriculum structure of the primary education master is not well highlighted by the characteristics of the primary education curriculum. The curriculum is accompanied by deep academic background, module structure is imbalanced, and professional theory courses and subjects are lack of substantial integration between the curriculum.

(2) Single teaching methods. Classroom teaching is a key factor to restrict the quality of graduate education. "Training program" provides that we should implement the principle of unity of theory and practice, adopting student participation, case analysis, group discussion, simulation teaching, and other teaching methods. Focus on case teaching, student self-study; organization counseling; invite subject experts or primary school teachers into the classroom. Most graduate students like the form of classroom discussions and teachers teach each other interspersed with the teaching, but in reality, more than half of teachers use classroom teaching methods. More seriously, up to $90 \%$ of teachers often or more use classroom teaching methods. [4] Experience sharing and classroom group discussion, practical operation and theoretical exploration, teachers in the classroom give questions, answers and after class students self-study, and other flip-style teaching methods rarely or even have not appeared, resulting in graduate students is difficult in limited time to form solid scientific research capacity and good professionalism. Most of the employers reflect the three most current lacks of full-time education specialty masters: the ability to find problems (56.5\%), the design capacity of the program (49\%) and the ability to solve the problem (42\%). [5] Therefore, the 
master's degree in primary education is designed to be closely related to the quality and professional characteristics of graduate students.

(3) Double-tutor system exists in name only. "Training Program" provides that: "employ experienced teachers as tutors in primary school, implement double-tutor system." Require each graduate students equipped with two tutors, one is familiar with the status quo of basic education and has high academic attainments of the college tutor, mainly to cultivate the theoretical quality of graduate students, pay attention to improve the scientific research ability of graduate students; the other is to employ primary school teachers with Advanced Level Accountant and basic education management experts as outside tutor, is mainly responsible for the practice of graduate students, designed to improve the practical ability of graduate students. However, in the specific implementation process, due to time constraints, labor remuneration, management system and other factors, there is little effort to guide graduate students to improve the standard of classroom teaching, do not really take the task of improving the ability of graduate students, usually just symbolic appeared in the graduation thesis defense meeting, the shallow level of the form, and did not play a substantive role. And the school tutor, because they have no primary school teaching experience, case analysis and practice link ability is obviously insufficient, the lack of practical ability to cultivate graduate students and professional skills training, deviate from the primary school teachers professional characteristics, dilute the professional degree graduate students, deviate from the professional purpose of postgraduate training purposes, and ultimately lead full-time primary school education specialty master tutor system exists in name only.

(4) Practical teaching link is 'anemia'. "Training Program" also clearly stipulates: "full-time education specialty master's practice teaching time is at least one year, to primary school for practical teaching shall not be less than six months." However, in the actual training process, the practice of teaching is serious "anemia", practical teaching time is not necessary to be guaranteed, practical ability can not be effectively cultivated, leading to diversified practical teaching alienation. First, the practice base has realistic difficulties, excellent primary school force to study, parents can not easily let graduate students have the opportunity to give lessons. While weak primary and secondary schools may give graduate students more practice opportunities, but often they are lack of experienced instructors. Second, the lack of stable funding for the protection of graduate students, the lack of guiding funds often affect the guidance of teachers and pay the impact of postgraduate internship quality and effectiveness. Third, many graduate students in the training department under the acquiescence of the use of decentralized practice are perfunctory, and most graduate students are also difficult to get enough exercise opportunities.

\section{Path Exploration on Full-time Primary Education Specialty Master Training}

It is of great significance to solve problems of cultivating the full-time primary education specialty master 's degree and explore paths of the cultivating quality of full-time primary education specialty master' s degree and promote the professional development of teachers.

(1) Highlight the professional characteristics of primary education as the core, optimize the curriculum structure. According to "Training Program" requirements, and surround the "Primary School Teacher Professional Standards" set up. First of all, in order to enhance the practicality and frontier of public basic courses, we can refine the theoretical courses such as "Principles of Education", "Youth Psychology Development and Education" and "Primary and Secondary Education and Scientific Research Methods" and integrate with the research method courses as " Education frontier research topic", "basic education curriculum frontier research topic" and " children's psychological development frontier research topic" three courses, training with modern education theory of primary school teachers. Secondly, in the professional compulsory course set, in order to cultivate all aspects of student teaching ability as the goal, highlight the professional and practical characteristics. Curriculum should be based on modern teaching ideas, ideas as the guide, set up with the quality requirements of primary school teachers consistent with the curriculum, such as primary school mathematics (Chinese) teaching materials analysis and teaching design courses. Finally, in the sub-direction of the required course set, mainly for students can be based on personal 
interests and development planning to choose different courses to focus on students education and teaching ability of different subjects.

(2) Adopt variety of interactions, enrich teaching methods. "National Mid-and-long Term Education Reform and Development Plan (2010-2020)" pointed out: learning and thinking are indispensable, advocate exploratory, researchful, cooperative, heuristic teaching methods. Therefore, teachers should adopt variety of teaching methods, such as inquiry-based teaching model, case teaching model and so on. First, teachers should use the exploratory teaching model in the process, the main content of the course should be learning and logical framework to explain clearly, for their learning content, the need for students to study the problem to provide the main reference and research methods guidance, and then organize and guide the students to discuss their findings in the classroom and make appropriate reviews and summaries. Second, teachers in the teaching process using case teaching, the first case should be presented, followed by students interpret the case, the last teachers and students discuss the case. At the same time, teachers should use modern information technology, and strive to enhance the primary school education specialty master's ability to innovate, explore the ability and learning ability to achieve transformation of student-centered teaching methods.

(3) Establish rigorous assessment procedures, improve double-tutor system. At present, most of our training department are based on "Full-time Education Specialty Master's Degree Graduate Students Instructional Training Program" to implement double-tutor training system. In the implementation of the double-tutor system, we should follow cooperation principle, process management principle, effectiveness principle of reference and other principles. First, we should be establish selection, tasks, responsibilities, assessment, evaluation, remuneration, rewards and other aspects of the rules. The description of the system and the rules should be embodied in the concrete, clear and operational. The implementation of dynamic management, the introduction of elimination model, the selection of academic and practical excellent teacher guide education master. Second, encourage and guide college and universities teachers who have strong interest and profound knowledge in basic education as school tutor, urge them to guide graduate students to cultivate their theoretical attainment and academic norms of guidance. Third, it is necessary to select the primary school teachers with excellent academic knowledge, rich teaching experience and outstanding management ability as the tutor outside the school, refine the rights and obligations of the outside tutors, strengthen the training of the tutors, enhance the salary of the tutors, innovate the way of guidance, and strive to make the theory and practice of the double-tutor system implement in a substantive play, continue to reinforce the primary education specialty master's basis and theoretical foundation.

(4) Through U-S symbiotic cooperation, infuse nutrition into practical teaching. U-S symbiotic cooperation is through cooperation between the university and primary school to promote the development of teacher education, through effective communication and integration between the university and primary school, jointly promote the integration of teacher education development. Primary school is the most rational place to cultivate teachers' wisdom, and has the absolute superiority of cultivating teachers' professional ability. [6]First, choose a fixed base school, and hire these famous primary school teachers or key teachers as part-time teachers in colleges and universities, let they assume certain practical courses' teaching work, effectively cultivate qualified primary school teachers. Second, U-S symbiotic cooperation can provide real education field for primary education specialty masters--primary school. Third, we should adopt the professional theory teaching and practice teaching alternately. First, in the first semester, systematically learn all kinds of theoretical knowledge. During the first half of the second semester, students are involved in the actual teaching problems found with reflection and other practical teaching activities. In the second half of the semester is focused on teaching, letting students have in-depth systematically study for problems in the process of practical teaching. Then, in the third semester, arrange for students to enter the school base practice. In the fourth semester, you can choose to practice internship outside the school, and complete the thesis at the same time. This combination of theory 
and practice, can achieve cycle of practice and reflection, promote students to improve the ability of teaching reflection.

\section{Conclusion}

It is of great significance to explore the training path of full-time primary specialty education master and promote the development of teachers' professional development. Primary education reform is necessary, but the reform is not in one day, the need is for concerted efforts from all walks of life, together, and I believe that through continuous efforts, primary education reform will obtain fruitful results.

\section{Acknowledgement}

This work is supported by Innovative training program for college students in 2017: Exploration and practice of "Chinese classics reading" into universities; Teaching reform project of Bohai university in 2015 (BDJG-15-YB-B-012); Postgraduate teaching reform project of Bohai university in 2016: Action research on "ability to advanced" under the primary school education professional master talent training mode reform; Research subject on teaching reform and on educational quality evaluation in Liaoning education evaluation association: Exploration and practice of "Chinese classics reading" into universities; "Professional degree graduate student case library" project of Bohai university in 2017: Primary school Chinese teaching design case library; Project of economic and social development in Liaoning in 2018: Research on the cultivation of core quality of normal education in the context of structural reform of supply side.

\section{References}

[1] Z. F. Huang, "Research on training mode of full-time Master of education based on Collaborative Innovation," Master's Degree of Southwest University, 2014.

[2] Z. F. Huang, "Research on training mode of full-time Master of education based on Collaborative Innovation," Master's Degree of Southwest University, 2014.

[3] Burton R. Clark, "Exploring place: Research and graduate education in Modern Universities," Zhejiang Education Press, 2001.

[4] H. Q. Fan, "Reflections on the training of full-time Master of Education: Based on the perspective of excellent teachers," Contemporary Teacher Education, vol. 32, no. 3, pp. 1-4, 2016.

[5] H. Q. Fan, "Reflections on the training of full-time Master of Education: Based on the perspective of excellent teachers," Contemporary Teacher Education, vol. 32, no. 3, pp. 1-4, 2016.

[6] X. Zhang, X. M. Zhang, "Research on the mechanism of symbiotic cooperation of teacher education U-S," Teacher education research, vol. 14, no. 1, pp. 29-34, 2012. 